УДК 657.1

DOI 10.18101/2304-4446-2020-4-118-126

\title{
ПОВЫШЕНИЕ ЭФФЕКТИВНОСТИ СИСТЕМЫ ВНУТРЕННЕГО КОНТРОЛЯ РАСЧЕТОВ С КОНТРАГЕНТАМИ В ОРГАНИЗАЦИИ
}

\section{(C) Одоева Ольга Исааковна}

кандидат экономических наук, доцент,

Бурятский государственный университет имени Доржи Банзарова

Россия, 670000, г. Улан-Удэ, ул. Ранжурова, 5

bahaevao@mail.ru

(C) Гомбоева Алла Николаевна

кандидат экономических наук, доцент,

Бурятская государственная сельскохозяйственная академия им. В. Р. Филиппова Россия, 670034, г. Улан-Удэ, ул. Пушкина, 8

allanicol@yandex.ru

\section{(C) Постникова Любовь Валерьевна}

кандидат экономических наук, доцент,

Российский государственный аграрный университет - МСХА им. К. А. Тимирязева Россия, 127550, г. Москва, Лиственничная аллея, 4

lpostnikova@gmail.com

Аннотация. В статье рассматриваются актуальные вопросы управления расчетов с контрагентами и оценки вероятности неисполнения контрагентами своих обязательств в современных условиях моратория на возбуждение дел о банкротстве. Определены основные проблемы развития системы внутреннего контроля расчетов с контрагентами в организации. Предложены варианты взаимодействия с контрагентом, попавшим под мораторий на банкротство, включая возможность продажи дебиторской задолженности. Проанализированы различные варианты осуществления внутреннего аудита в организациях: от отделов по работе с просроченной задолженностью до постановки и оптимизации системы внутреннего контроля специализированной компанией, включая косорсинг и аутсорсинг внутреннего аудита. Авторами для улучшения деятельности системы внутреннего контроля в статье определены приоритетные для решения проблем основные направления развития бухгалтерского учета расчетов с контрагентами, в том числе даны рекомендации по проверке контрагентов в кризис.

Ключевые слова: внутренний аудит; внутренний контроль; дебиторская задолженность; кредиторская задолженность; контрагент; оптимизация системы.

\section{Для цитирования}

Одоева О. И., Гомбоева А. Н., Постникова Л. В. Повышение эффективности системы внутреннего контроля расчетов с контрагентами в организации // Вестник Бурятского государственного университета. Экономика и менеджмент. 2020. № 4. С. 118-126.

Дебиторская и кредиторская задолженности - неизбежное следствие существующей в настоящее время системы денежных расчетов между организациями, 
при которой всегда имеется разрыв времени платежа с момента перехода права собственности на товар, между предъявлением платежных документов к оплате и временем их оплаты $[1$, с. 20]. Работа руководителя и главного бухгалтера организации обязательно должна включать мониторинг и оценку вероятности неисполнения контрагентами своих обязательств.

Правительство РФ 3 апреля 2020 г. ввело мораторий на возбуждение дел о банкротстве сроком на полгода ${ }^{1}$. Мораторий на возбуждение дел о банкротстве по требованию кредиторов в наиболее пострадавших от COVID-19 отраслях может быть продлен еще на три месяца. Он действует в том числе в отношении системообразующих и стратегических предприятий. Очевидно, что эти предприятия имеют большой запас прочности, чего не скажешь об их контрагентах, для которых получение своевременной оплаты - это зачастую вопрос выживания, не говоря уже о том, что некоторые крупные заказчики платят своим поставщикам исключительно по исполнительному листу или заявлению на банкротство.

Мораторий распространяется на 1,3 млн компаний и индивидуальных предпринимателей, и это примерно треть всего активного бизнес-сообщества страны. Очевидно, что большинство контрагентов стратегических и системообразующих предприятий - это менее крупные и уязвимые организации, которые лишились законных рычагов воздействия на своих должников ${ }^{2}$.

Частично компенсировать потерю спроса российскому бизнесу должны меры государственной поддержки. Однако они касаются только бизнеса, попавшего в сложную экономическую ситуацию из-за распространения коронавируса. Вероятно, меры государственной поддержки в отношении тех, кто лишен возможности самостоятельно разрешить сложившуюся ситуацию, будут корректироваться и расширяться. Проблема в том, что сейчас нет «непострадавших».

В этих условиях «система внутреннего контроля является актуальной для российского предпринимательства, так как он является неотъемлемой частью системы управления в целом. Достижение целей бизнеса зависит в основном от эффективности работы системы контроля в организации» ${ }^{3}$.

Хорошо поставленный внутренний контроль расчетов с покупателями и поставщиками позволяет иметь доступную аналитику и полный контроль над расчетными операциями и их оценкой в бухгалтерском и налоговом учете. Система внутреннего контроля как минимум выполняет функцию «последконтроля», а как максимум - обеспечивает достоверность всех участков бухгалтерского учета и формирования отчетности организации. Оценку системы внутреннего контроля необходимо проводить в разрезе участков учета [3, c.10].

В ходе нашего исследования применялись различные тесты оценки состояния системы внутреннего контроля расчетов с покупателями и заказчиками и расчетов с поставщиками и подрядчиками. Исходя из данных тестирования определяется риск системы контроля расчетов с контрагентами.

\footnotetext{
${ }^{1}$ Гарант: информационно-правовой портал [Электронный ресурс]. URL: http://garant.ru/ (дата обращения: 10.09.2020).

${ }^{2}$ РБК: информационное агентство: сайт [Электронный ресурc]. URL: https://pro.rbc.ru/ (дата обращения: 01.10.2020).

${ }^{3}$ Главбух: официальный сайт [Электронный ресурс]. URL: https://www.glavbukh.ru (дата обращения: 10.09.2020).
} 
Что делать, если контрагент может воспользоваться мораторием на банкротство? Необходимо оценить степень благонадежности должника, для этого можно воспользоваться одним из существующих на рынке автоматических сервисов. А также уточнить сумму требований к контрагенту, штрафные санкции в период действия моратория начисляться не будут. Рассчитать сроки возврата средств в оптимистичном и пессимистичном вариантах. При расчете учитывать шестимесячную отсрочку, возможное затягивание должником сроков взыскания и его вероятное банкротство. Определить источники альтернативного финансирования кассовых разрывов своей организации с учетом стоимости привлеченных денег. Предпринять необходимые действия для сокращения расходов своего предприятия на срок действия моратория и шесть-девять месяцев после его окончания, так как это средний срок взыскания задолженности, без учета исполнительного производства.

Мы предлагаем следующие варианты взаимодействия с контрагентом, попавшим под мораторий на банкротство:

1. Согласовать график погашения задолженности с контрагентом-должником. Договориться с ним о сроках ее погашения, закрепить договоренности гарантийным письмом или соглашением о рассрочке оплаты. С таким документом при необходимости можно быстрее получить решение суда о взыскании.

2. Начать взыскание долга либо ожидать окончания срока действия моратория, если исполнительный лист уже получен. Это самый плохой вариант: за полгода наберется большое количество непогашенных и просуженных требований, которые кредиторы единовременно предъявят должнику после окончания мораторного срока.

3. Получить финансирование под задолженность по договору факторинга. Однако факторинговые компании, как правило, кредитуют далеко не каждый долг. Если задолженность проблемная, или нужны средства под судебный долг или для разовой сделки, то можно получить финансирование на сумму до 50\% от уступаемого права требования. За такую услугу придется заплатить комиссию. В дальнейшем можно погасить задолженность, вернув себе право требования. Либо факторинговая компания, дождавшись погашения от должника, выплатит разницу за вычетом полученного финансирования.

Кроме того, есть возможность предоставить долг в отступное по обязательствам бизнеса. Как правило, банки не рассматривают дебиторскую задолженность как самостоятельный залоговый инструмент. Но бывает, что дебиторская задолженность закладывается в дополнение к другим обеспечениям. Надо будет найти того, кто рискнет купить долг компании, зная, что через шесть месяцев к ней выстроится очередь из кредиторов с заявлениями на банкротство. Чем больше рисков и длиннее сроки возврата средств, тем меньше стоимость долга. Соответственно, дисконт при продаже обязательства будет выше и в среднем составит не менее $50 \%$ от суммы основного долга.

Важными параметрами при определении дисконта являются сроки взыскания долга, уровень устойчивости и платежеспособности должника. В расчет пойдут:

- сумма исковых требований к должнику;

- суммы по его исполнительным производствам (сколько исполнено, сколько нет и в течение какого периода); 
О. И. Одоева, А. Н. Гомбоева, Л. В. Постникова. Повышение эффективности системы внутреннего контроля расчетов с контрагентами в организации

- сумма долгосрочной кредиторской задолженности;

- наличие задержек по выплате зарплат сотрудникам;

- наличие действующих государственных контрактов и т. д.

Таким образом, решение о продаже долга стоит принимать, только составив представление о финансовом состоянии должника и оценив запас прочности своей компании на год-полтора.

В настоящий момент, когда во всем мире объявлена пандемия коронавируса, собственнику важно сохранить стабильность своей компании и устранить риски, связанные с участившимися банкротствами заказчиков и клиентов. Для этого надо провести тщательную работу с дебиторской задолженностью и заново оценить надежность своих контрагентов. Для улучшения деятельности определены приоритетные для решения проблем основные направления развития:

- повышение эффективности системы внутреннего контроля;

- оптимизация политики управления дебиторами и кредиторами;

- рост резервов повышения прибыли и рентабельности на предприятии;

- совершенствование организации учета на предприятии.

Повышение эффективности системы внутреннего контроля достигается за счет: оценки рисков; формализации свода правил контрольных процедур, политик; перераспределения полномочий, автоматизации процессов, внедрения формализованного документооборота и т. д.

Как проверить контрагента в кризис? Все доступные онлайн-данные о компаниях можно условно поделить на те, которые обновляются один раз в год, и те, которые обновляются ежеквартально. В сложившейся ситуации внимание должно быть направлено именно на актуальные данные, так как, например, бухгалтерская отчетность за 2018 г., особенно в сегменте малого бизнеса, уже неинформативна.

Чтобы получить актуальное представление о состоянии контрагента и возможных рисках сотрудничества с ним, необходимо изучить свежие данные по компании в доступных источниках. Например, не появилось ли новых сообщений о значимых изменениях у компании. Можно обнаружить и оценить изменения в лицензиях, залогах, узнать о том, что компания вступила в саморегулируемую организацию (СРО) или, напротив, была исключена из нее. Особенно тщательно проверить, нет ли в карточке компании свежего сообщения о намерении кредитора обратиться в суд с заявлением о банкротстве. Сейчас, прежде чем подать иск о несостоятельности, требуется за 14 дней опубликовать соответствующее сообщение. А также проверить, поданы ли новые иски к данной организации, уточнить в картотеке арбитражных дел и решений, как проходит процесс в уже имеющихся судебных делах. Проверить открытые судебные дела, по которым компания выступает ответчиком. Обратить внимание на их обстоятельства и на то, на какую сумму к ней поданы иски. Не стоит обходить вниманием и дела, где контрагент выступает истцом, так как дебиторская задолженность - это тоже актив. Если должник контрагента обанкротился, то и на него самого это повлияет.

Необходимо оценить динамику появления дел с участием контрагента и заявленных в них сумм. Если количество открываемых дел с каждым месяцем растет, это плохой знак. Настоятельно рекомендуем с помощью специального сервиса 
поставить контрагента на отслеживание, чтобы не пропускать новые иски, например о несостоятельности.

Для максимально полной оценки долговой нагрузки контрагента нужно проверить количество и сумму исполнительных производств на сайте Федеральной службы судебных приставов.

Если найдены открытые исполнительные производства, то оценить их суммы и то, как долго открыты исполнительные листы. Если суммы крупные и исполнительные листы открыты длительное время, это плохо характеризует контрагента как платежеспособную компанию. Есть ли завершенные исполнительные листы не по оплате - они могут появиться в случаях, когда пристав не обнаружил саму компанию по юридическому адресу либо ее имущество.

Показателем того, что контрагент хочет завершить свою деятельность, может быть одновременная смена руководителя и владельца компании и/или смена места регистрации компании. Эти изменения можно увидеть в ЕГРЮЛ. Кроме этого, необходимо обратить внимание на записи в ЕГРЮЛ о ликвидации или реорганизации юридического лица. Если обнаружится запись о реорганизации юридического лица, то нужно обратить внимание на ее вид. Реорганизация через слияние, присоединение или выделение часто используется контрагентами как альтернатива ликвидации. Тут же в ЕГРЮЛ нужно посмотреть, кто является совладельцами компании, если это юридические лица, то можно проверить их судебную нагрузку и то, не обанкротились ли они. Актуально проверить наличие заблокированных счетов на сайте того же ФНС. Если они есть, это не критично при отсутствии крупных исков в арбитраже и открытых исполнительных листах.

На сайте госзакупок необходимо выяснить, как обстоят дела с государственными контрактами и оценить динамику заключаемых и исполняемых контрактов. Хорошо, если компания регулярно год от года заключает контракты. Внимательно изучить карточки, особенно крупных контрактов, там часто можно увидеть, как исполняется контракт, сколько денег уже заплачено контрагенту и сколько ему еще осталось заплатить.

Обязательно проверьте полученную информацию по телефону. Можно позвонить по известным номерам контрагента, например главному бухгалтеру, узнать у него о статусе вашего контрагента, а также всегда можно позвонить заказчику работ по госконтракту вашего контрагента и попросить оценить его деятельность. Дополнительно можно связаться с сотрудниками компании контрагента. Возможно, кто-то из сотрудников расскажет, что все в компании сидят на чемоданах, потому что она завершает свою деятельность.

Но скорость, объективность и актуальность выводов при самостоятельной обработке данных могут быть недостаточными для принятия своевременных решений. Каждый день появляется свежая информация: о новых ограничениях, связанных с распространением коронавируса, планах по борьбе с ним, мерах поддержки предприятий из разных отраслей и т. д. В результате предпринимателям приходится ежедневно фильтровать новые данные, определять факторы, которые могут повлиять на их бизнес, и корректировать процессы.

Для быстрой оценки текущей ситуации можно использовать сервисы, которые уже учитывают в своих алгоритмах изменения по различным параметрам. Существуют финансовые компании, которые занимаются инжинирингом на рынке 
долговых обязательств, они разрабатывают и выводят на рынок продукты для работы с дебиторской задолженностью в виде моделей экспертной автоматической оценки платежеспособности компании, а также предоставляют предприятиям малого и среднего бизнеса финансирование по договорам цессии и факторинга.

Когда ресурсы бизнеса на исходе, важно оценивать риски сотрудничества с компаниями, которые будут «кредитоваться» за ваш счет, выполняя условия договора по решению суда и получая таким образом средства под размер действующей ключевой ставки Банка России.

Поэтому отдел внутреннего аудита является структурой, способной выполнять функции контроля подготовки объективной финансовой информации, оценки эффективности системы внутреннего контроля, выявления и управления рисками, поскольку внутренние аудиторы способны выполнять значительный объем контрольных функций, возложенных на руководство организации. Немаловажно и то, что отделы внутреннего аудита используются на предприятиях в подавляющем большинстве стран и на практике подтверждают свою эффективность.

Большинство современных руководителей отмечает, что эффективная работа подразделения внутреннего аудита играет большую роль в достижении целей компании. Руководители функции внутреннего аудита, в свою очередь, также должны понимать важность повышения качества деятельности внутреннего аудита и стремиться соответствовать лучшей мировой практике в этой области.

В компании должна быть создана команда профессионалов, включающая в себя процессного менеджера, аудиторов, профильных специалистов, менеджера проекта. Все специалисты должны иметь значительный практический опыт работы, знать особенности и правила постановки количественно-качественного учета на предприятиях, хранения и переработки, постановку производственного учета на предприятиях транспорта.

Руководителю отдела нужно обладать необходимым практическим опытом реализации проектов как по оценке качества деятельности внутреннего аудита, так и по построению самой функции внутреннего аудита и проведению аудита в компаниях различных отраслей, а также хорошо знать и понимать российскую специфику организации работы функции внутреннего аудита, обладать компетенциями по международным стандартам внутреннего аудита, знать руководство для внутреннего аудитора по применению кодекса этики и стандартов, а также методологию по организации и внедрению программы гарантии и повышения качества внутреннего аудита.

В соответствии со стандартами внутреннего аудита руководитель отдела компании должен разработать и осуществлять программу по обеспечению качества, а также и анализ документов, регулирующих деятельность отдела внутреннего аудита в компании (устав, организационная структура, методология проведения, внутренняя политика и процедура внутреннего аудита).

Внутренние аудиторы способны помочь менеджерам обеспечить защиту от ошибок и злоупотреблений, определить «зоны риска» и возможности устранения будущих недостатков или недостач, идентифицировать и «усилить» слабые места в системах управления и выявить те принципы управления, которые были нарушены. Все эти действия дополняются обсуждением проблем с высшими ор- 
ганами управления компании, нужды и предложения которых и определяют процедуры внутреннего аудита (внутренние аудиторы должны обеспечить управляющих любой информацией, касающейся компетенции этих специалистов).

Всесторонний анализ позволит объективно оценить все аспекты деятельности функции системы внутреннего аудита, ее достоинства и недостатки. Он включает:

1. Интервью с потребителями услуг внутреннего аудита, представителями высшего руководства компании, руководителями бизнес-подразделений, в которых проводились аудиты (выборочно), а также с руководителем и сотрудниками функции внутреннего аудита (выборочно).

2. Проведение опроса (анкетирование) высшего руководства компании и сотрудников внутреннего аудита (анонимно), результаты которого будут агрегированы и представлены в отчете КПМГ.

3. Анализ проектной документации по проведенным внутренним аудиторским проверкам (выборочно), в том числе аудиторский план, рабочие бумаги, отчеты внутреннего аудита, коммуникации.

4. Контроль устранения замечаний

Помимо подготовки отчета по результатам оценки внутреннего аудита необходимо оценивать эффективность внедрения предложенных рекомендаций и принятых мер. По результатам подготавливается финальный отчет, в котором будет отражен статус исправления выявленных недостатков. Такой подход позволит получить максимальную выгоду от внедрения системы внутреннего аудита.

Кроме того, требуются внешние оценки деятельности внутреннего аудита, которые должны проводиться как минимум один раз в пять лет квалифицированным независимым оценщиком или группой оценщиков, не являющихся сотрудниками организации. И чего вытекает наша вторая рекомендация. Служба внутреннего аудита может быть организована внутри организации. Вместе с тем многие организации считают целесообразным частичный или полный аутсорсинг функции внутреннего аудита.

Следующим направлением повышения эффективности внутреннего контроля является помощь внешней специализированной компании по оптимизации системы внутреннего контроля.

В настоящее время множество компаний в области внутреннего аудита предлагают целый спектр возможностей по оказанию помощи, поддержки и оптимизации рабочего процесса, начиная с тренинга ответственных лиц, косорсинга и вплоть до полной передачи всех функций по осуществлению внутреннего контроля аудиторской организации.

Под постановкой, оптимизацией системы внутреннего контроля мы понимаем внедрение комплекса мероприятий, направленных на решение вышеназванных задач. Результатом оказания услуг является эффективная система внутреннего контроля, отвечающая масштабам бизнеса предприятия.

Использование специализированной компании может быть в виде:

- постановки и оптимизации системы внутреннего контроля специализированной компанией;

- косорсинга внутреннего аудита, когда служба внутреннего контроля создается в рамках организации, а специализированная компания привлекается к выполнению отдельных аудиторских заданий (внешний консультант); 
О. И. Одоева, А. Н. Гомбоева, Л. В. Постникова. Повышение эффективности системы внутреннего контроля расчетов с контрагентами в организации

- аутсорсинга внутреннего аудита - функция внутреннего аудита полностью передается специализированной компании (внешнему консультанту).

За постановкой и оптимизацией системы внутреннего контроля большинство компаний обращаются в аудиторские компании. Специализированная компания предлагает широкий спектр услуг в области внутреннего аудита. Косорсинг это организация рабочего процесса контроля путем разделения полномочий между подразделениями компании и внешней организацией [2]. Косорсинг иногда характеризуют как частичный аутсорсинг.

Часто внутреннего аудита недостаточно для полного понимания картины, это может быть связано с недостаточным опытом сотрудников компании. Часто в компании нет специалиста, который может провести аудит в каком-нибудь специфичном отделе. Используя косорсинг, можно получить более объективную и непредвзятую оценку происходящего за счет привлечения профессиональных аудиторских кадров. Также появляется возможность получить доступ к самым передовым методикам и технологиям проведения внутреннего аудита.

Стоит отметить, что косорсинг - значительно более затратный способ организации контроля, особенно в сравнении с аутсорсингом. Поскольку придется оплачивать и работу своих сотрудников, и аутсорсинг. Но в перспективе косорсинг может позволить сэкономить значительные средства.

Аутсорсинг внутреннего аудита дает оптимизацию затрат на проведение внутреннего аудита. Передача функций на компетентный аутсорсинг компании, оказывающей услуги в этой области, позволит организации проводить ревизии через доступ к сети специалистов. Оптимизированный подобным образом внутренний аудит оказывает помощь руководству организации в исполнении функции контроля в рамках управления предприятием с помощью независимых проверок и способствует успеху деятельности компании.

Таким образом, предложенные рекомендации позволят соблюдать требования к системе внутреннего контроля расчетов с контрагентами. Не надо ждать помощи со стороны. Необходимо самостоятельно оценивать ситуацию и принимать сложные решения, которые позволят компании перейти в «завтра», а не остаться во «вчера».

\section{Литература}

1. Богомолов А. М. Управление дебиторской и кредиторской задолженности как элемент внутреннего контроля в организации // Современный бухучет. 2015. № 5. С. 20-22.

2. Карзаева Н. Н. Система внутреннего контроля за ведением бухгалтерского учета и составлением бухгалтерской отчетности // Бухучет в сельском хозяйстве. 2016. № 10. С. 65.

3. Кондрашова Н. Г. Внутренний финансовый контроль как инструмент выявления и предупреждения экономических преступлений // Экономика и социальная сфера: проблемы взаимодействия и развития: сборник научных статей по материалам международной научно-практической конференции / под ред. Т. Э. Пироговой, Д. К. Никифорова. М.: ТРП, 2018. С. 9-13. 


\section{EFFECTIVIZATION OF THE SYSTEM FOR INTERNAL CONTROL OF PAYMENTS TO COUNTERPARTIES IN ORGANIZATIONS}

Olga I. Odoeva

Cand. Sci. (Econ.), A/Prof.,

Dorzhi Banzarov Buryat State University

5 Ranzhurova St., Ulan-Ude 670000, Russia

bahaevao@mail.ru

Alla N. Gomboeva

Cand. Sci. (Econ.), A/Prof.,

Filippov Buryat State Agricultural Academy

8 Pushkina St., Ulan-Ude 670034, Russia

allanicol@yandex.ru

\section{Lyubov V. Postnikova}

Cand. Sci. (Econ.), A/Prof.,

Russian State Agrarian University -

Timiryazev Moscow Agricultural Academy

4 Listvennichnaya Alley, 127550 Moscow, Russia

lpostnikova@gmail.com

Abstract. The article discusses the topical issues of managing payments to counterparties and estimated probability of counterparties failing to fulfill their obligations in the current context of a moratorium on initiating bankruptcy cases. We have determined the key development problems of the system for internal control of payments to counterparties in organizations, and proposed ways for interaction with a counterparty that have fallen under a moratorium on bankruptcy, including the possibility of selling receivables. The article analyzes various options for the implementation of internal audit in organizations: from nonperforming loan management to optimization of the internal control system by a specialized company, including co-sourcing and outsourcing of internal audit. In order to improve the performance of the internal control system, we have defined the main trends in development of accounting payments to counterparties, and gave recommendations for checking counterparties in a crisis.

Keywords: internal audit; internal control; accounts receivable; accounts payable; counterparty; system optimization.

Статья поступила в редакцию 02.10.2020; одобрена после рецензирования 30.10.2020; принята к публикации 30.10.2020. 